\title{
Simulation of seismic liquefaction: 1-g model testing system and shaking table tests
}

\author{
Nurhan Ecemis \\ Civil Engineering Department, Izmir Institute of Technology, Izmir, Turkey
}

(Received 5 October 2012; accepted 2 August 2013)

\begin{abstract}
In this paper, we focus on the development and performance of the 1-g model testing system to monitor the liquefaction occurrence of saturated soils, under subsequent one-dimensional shake table tests. The system is composed of one-dimensional laminar box, cone penetration system, soil model, system for hydraulic soil pumping to achieve loose soil deposit, instrumentation and associated testing hardware. In order to simulate the free-field conditions in the laboratory, the laminates slide on each other using rollers placed between each laminate. The static calibration test results demonstrate that the friction effects between the laminates and the rollers are satisfactorily low. The loosest and the most liquefiable sand deposit is prepared inside the laminar box by hydraulic filling process and subjected to four subsequent shaking tests at different intensities. First, the laminar box and shake table performance is verified by using time-histories of acceleration and displacement test results. Then, the measured data inside the soil and on the laminates are compared with the numerical model. The previously calibrated numerical model UBCSAND which shows the seismic loading conditions in the free field is used in the simulations. Those shake table test results and the numerical simulations of the box and the soil indicate that the usefulness of the laminar box system for shaking table tests is satisfactory for dynamic model tests in 1-g gravity.
\end{abstract}

Keywords: sand; shake table test; laminar box; liquefaction; UBCSAND model; soil model preparation

\section{Introduction}

Liquefaction in loose saturated sands and silty soils continues to be a substantial cause of earthquake damage to geotechnical structures, transportation systems, deep foundations and other infrastructure systems located in regions of moderate to high seismicity. Historically, researchers have conducted aerial surveys to study the failures due to liquefaction at various places (Elgamal \& Zeghal, 1992; Hamada, Yasuda, Isoyama, \& Emoto, 1986; O'Rourke et al., 1992). However, the main limitation with these aerial surveys was that they gave information about the sites before and after an earthquake but not during the earthquake. In order to fill in the necessary gaps, model studies are essential to predict the displacements, accelerations, and pore water pressures caused by a specified input motion. Researchers recently have been using large scale 1-g shaking table tests (He et al., 2006; Suzuki, Tokimatsu, Sato, \& Abe, 2005; Tamura \& Tokimatsu, 2005; Towhata, Sesov, Motamed, \& Gonzalez, 2006; Thevanayagam et al.,

*Email: nurhanecemis@iyte.edu.tr 
2009 ) or the augmented gravity field centrifuge tests (Abdoun, Dobry, O'Rourke, \& Goh, 2003; Arulanandan \& Scott, 1993; Brandenberg, Boulanger, Kutter, \& Chang, 2005; Dobry, Taboada, \& Liu, 1995; Elgamal, Zeghal, Taboada, \& Dobry, 1996; Haigh \& Madabhushi, 2005) to study the behaviour of soil under more realistic seismic loading conditions. Both shaking table and centrifuge model tests have certain advantages and limitations. Shaking table tests have the advantage of well controlled large amplitude and easier experimental measurements than centrifuge tests. Their use is also required if the purpose of the test is to understand the basic failure mechanisms. Centrifuge tests can also be used for measurement of displacements, input and induced accelerations and pore water pressures under field stress conditions. However, the centrifuge tests have two main problems that not all scaling laws can be satisfied simultaneously and that a dense instrument group cannot be used to measure the entire soil response.

In this study, recently developed 1-g shake table is used to simulate the liquefaction of loose saturated sand under one-dimensional shaking. The soil model cannot be directly mounted on shaking table because of the requirements of confinement. Therefore, a flexible box system composed of 24 layers, which can move with a low friction on each other and simulate the free-field conditions effectively during seismic loading, is developed based on the criteria specified by Whitman and Lambe (1986). The research reported in this paper focuses on the design, development and calibration procedures of the laminar box. Successively, four shaking tests are applied to the saturated sand deposit to illustrate the effectiveness of the laminar box system for one-dimensional shaking table tests. The piezocone penetration tests (CPTu) conducted after the preparation of the model show that the homogeneity and density of the soil throughout the depth are reasonably low for the initial liquefaction. The system also involves instrumentation to collect detailed displacement, acceleration and pore pressure data on the progression of the liquefaction phenomenon during each shaking. First, the recorded accelerations obtained by different types of sensors at the same locations are crosschecked to verify the quality of the measured data. Next, the recorded settlement, accelerations, excess pore pressures and lateral deformations are compared with the numerical model to verify the usefulness of the laminar box system for shaking table tests. In this study, the previously calibrated UBCSAND model version 904aR (Beaty \& Byrne, 2011) is used for the simulations. Within this constitutive model, the relationship between the shear stress and the total shear strain of the soil can be approximately represented by a hyperbolic equation. When Beaty and Byrne (2011) formulating the UBCSAND model, they recognised that much of the non-linear response of the soil was plastic. Hence, they assumed that the relationship between shear stress and plastic shear strain could also be reasonably represented by a hyperbolic relationship. The model is incorporated into the dynamic coupled stress-flow finite difference programme FLAC (Fast Lagrangian Analysis of Continua) in order to capture the plastic strains that occur at all stages of loading. Several researchers (Beaty \& Byrne, 1998; Byrne et al., 2004; Puebla, Byrne, \& Phillips, 1997; Ziotopoulou, Boulanger, \& Kramer, 2012) have reported the successful validation of UBCSAND model for predicting the behaviour of liquefiable soil measured in laboratory tests or field case histories. Puebla et al. (1997) and Byrne et al. (2004) noted that UBCSAND and FLAC were successful in predicting deformation and pore water pressure measurements in a centrifuge model test used to design the field programme. Beaty and Byrne (1998) utilised UBCSAND to perform a 1D simulation of the response of the instrumented Wildlife Site in Southern California where liquefaction and lateral spreading occurred during the 1987 Superstition Hills Earthquake. They were also able to predict the time at which liquefaction occurred 
reasonably well. Ziotopoulou et al. (2012) indicated that the results obtained using the UBCSAND model for the liquefiable layers provided realistic and reasonable responses. In addition to the study of the $1-\mathrm{g}$ model testing system performance, the role of relative density on progression of the liquefaction phenomenon is considered by using the subsequent shaking table test results.

\section{1-g model testing system}

A 1-g model testing system is developed on the one-degree of freedom shake table to test large soil specimens under 1D seismic loading. Shake table is supported by a $1 \mathrm{~m}$ thick strong floor with an area of $51 \mathrm{~m}^{2}$ which is located at Izmir Institute of Technology structural engineering laboratory. The aluminium testing platform is a rectangle with $2 \times 0.8 \mathrm{~m}^{2}$ area and $8 \mathrm{~mm}$ thickness. The shake table sits on the eight ball bearings, each with the payload capacity of $2000 \mathrm{~kg}$. The maximum payload capacity of the shake table is $16000 \mathrm{~kg}$ and allowable maximum peak to peak displacement in the longitudinal direction at the top of the box is $1 \mathrm{~m}$. A 1 -g model testing system built on the shake table is composed of (a) 1D laminar box, (b) system for laboratory hydraulic placement of $1.4 \mathrm{~m}$ height loose soil deposit and (c) cone penetration system.

\subsection{One-dimensional laminar box}

In general, laminar box containers (1) should have perfectly flexible walls to accurately represent the free-field seismic site response when subjected to shaking; and (2) should be ideally massless so that soil deformation during shaking is driven by the soil mass rather than the inertia of the box. Figure 1 shows a schematic view of the proposed laminar box on the shaking table. Here, to provide flexible but unyielding side boundaries as in the field, laminar box is composed of 24 identical-shaped aluminium rings (hereafter named as laminates). Aluminium is chosen to reduce the weight of the laminates and their inertial effects on the soil movements. Therefore, the acceleration

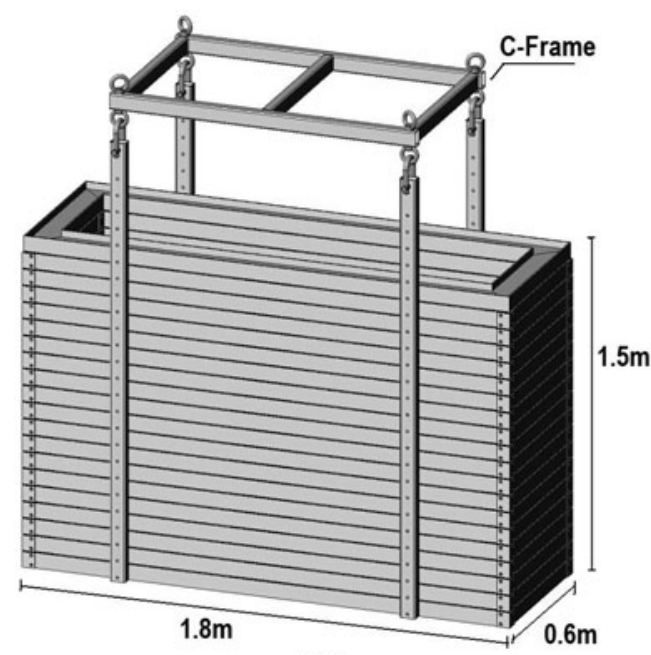

(a)

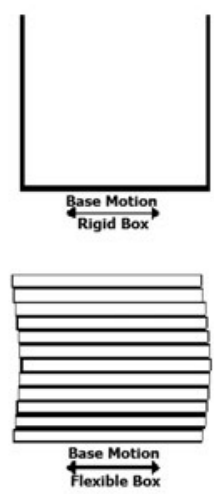

(b)

Figure 1. (a) Schematic view of the laminar box; (b) Rigid and flexible walls. 
(a) inside the soil without the influence of the box will be smaller than the measured acceleration $\left(a^{\prime}\right)$ of the soil within the laminates. Considering $\mathrm{m}_{1}$ to be the mass of soil within a laminate, and $\mathrm{m}_{2}$ the mass of the corresponding laminate, then, the acceleration of the soil inside the box will be;

$$
a^{\prime}=\left(\frac{m_{1}+m_{2}}{m_{1}}\right) a
$$

To eliminate the effect of inertia induced by the mass of the box, the measured acceleration needs to be corrected by $m_{1} /\left(m_{1}+m_{2}\right) \cdot m_{1}$ depends on the density of the tested soil. Assuming the box is filled with a soil having the saturated unit weight $1900 \mathrm{~kg} / \mathrm{m}^{3}$, the correction factor is at most .68 . However, the best way to assess the behaviour of the system is to examine the results of the liquefaction experiments themselves.

The laminates are made of aluminium I-beams, each $57 \mathrm{~mm}$ wide and $108 \mathrm{~mm}$ deep. In flexible box, the shear stiffness of the walls is limited to the friction between the layers and the influence of rubber membrane inside the box (Fiegel, Idriss, \& Zeng, 1994). In order to significantly reduce the friction between the layers and to make the distribution uniform, rings are separated and supported by eight rollers (diameter of $47 \mathrm{~mm}$ ) mounted between each laminate. Rollers are placed inside the top channel of the I-beam; four of them on the north side and others on the south side (Figure 2(a)). When the laminates slide with respect to one another, the rollers ride on the bottom of the laminate. When the laminates are stacked together, they sit on each other resting on rollers. The base laminate (L1) is rigidly tied to the shake table with L-profiles as shown in Figure 2(b). The components of laminates consist of rollers, box and rubber stoppers, plates under rollers, profiles near rollers and angle brackets. The $50 \mathrm{~mm} \times 180 \mathrm{~mm}$ box stoppers are inserted inside the long side of the laminates to prevent any lateral movement and the rotation. The $50 \mathrm{~mm} \times 606 \mathrm{~mm}$ box stoppers are also introduced at the short side of the laminates to limit the longitudinal displacement

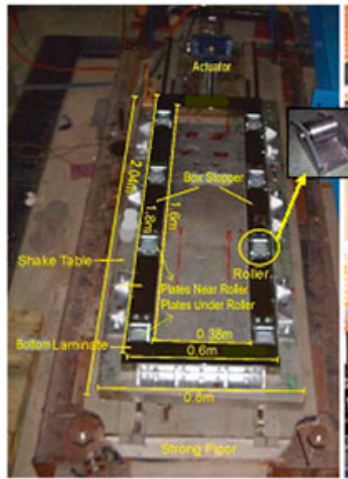

(a)

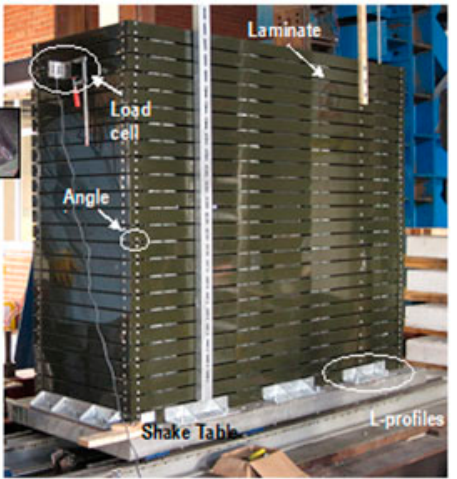

(b)

Figure 2. (a) Top view of the bottom laminate connected to the shake table; (b) General view of the laminar box fastened on the shaking table (actuator; shake table; laminates; strong floor; rollers; box stoppers; rubber stoppers; plates under rollers; plates near rollers; angle brackets; and L-profiles). 
between each laminate. Furthermore, $10 \mathrm{~mm}$ thick rubber is attached to each side of the box stoppers to reduce development of reflected waves and noise during the shake table tests. Each laminate is allowed to slide laterally at a maximum of $14 \mathrm{~mm}$ in the longitudinal direction relative to the adjacent laminate. Maximum cumulative displacement at the top of the laminar box is $320 \mathrm{~mm}$. A $1 \mathrm{~mm}$ thin EPDM rubber membrane bag is used inside the container to maintain air tightness and not to allow the soil to come into contact with the walls directly. Its stiffness is sufficiently small compared to that of the soil. The top laminate (L24) weighs about $13 \mathrm{~kg}$ while the remaining 23 laminates weigh around $34 \mathrm{~kg}$ with their components. The total weight of the laminar box without soil is $795 \mathrm{~kg}$.

A small vertical gap of $5 \mathrm{~mm}$ is provided between any adjacent laminates to prevent contact interference between laminates during longitudinal sliding of the laminates. This makes the maximum height of the box $1.5 \mathrm{~m}$ when all laminates are stacked together. The external dimensions of the box are $1.8 \mathrm{~m}$ in length by $.6 \mathrm{~m}$ in width. Thus, $11 \mathrm{~cm}$ deep I-beam gives clear internal dimensions of the box as $1.6 \times .38 \times 1.5 \mathrm{~m}^{3}$. Constructing laminar box having a rectangular cross section is easier, and since the measuring points are usually located in the centre of the cross section, the prospective stress concentration in the corners has little effect on the test results (Jafarzadeh, 2004). Also, at the rectangular shape box, the rollers which move longitudinally reduce friction and the possibility of lateral buckling. Static pull out tests are conducted at the 1D laminar box without soil to study the friction effect on the performance of the box. As illustrated in Figure 2(b), the load cell with a capacity of $50 \mathrm{~kg}$ is attached to the laminates, and static force applied on each layer is measured. The measured force $\left(F_{\mathrm{s}}\right)$ on each layer, being a function of the coefficient of friction $(\mu)$ between the layers and the laminate weight from the top, is observed to increase with depth. Figure 3 shows the variation of static force on the box with depth. The maximum force required to overcome the static friction is found to be $5.2 \mathrm{~N}$ on the bottom layer. The average coefficient of friction between the rollers and the laminates is found to be $.36 \%$. Assuming soil to be placed over the entire depth and considering a soil saturated unit weight of $1900 \mathrm{~kg} / \mathrm{m}^{3}$ and a friction angle of $20^{\circ}$, the soil

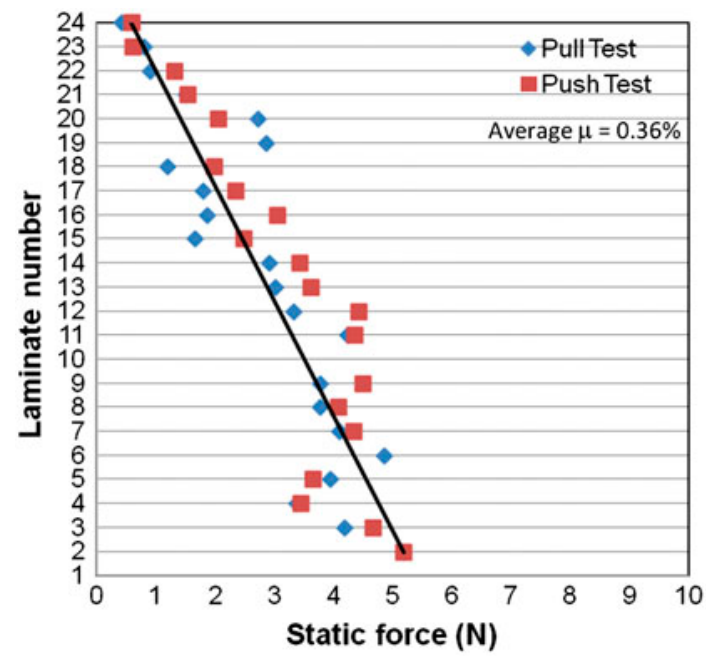

Figure 3. Static pull out test results: Static force to move different laminates of the box. 
resistance near the bottom will be around $6500 \mathrm{~N}$. This is around .1\% or less of the friction force inside the soil model in this level. These results demonstrate that the friction effects between the laminates and the rollers are satisfactorily low.

\subsection{Preparation of the model}

The $1.4 \mathrm{~m}$ deep saturated loose clean sand layer is placed inside the laminar box using hydraulic fill deposition technique (Whitman, 1985). By the application of this method, Thevanayagam et al. (2009) prepared loose Ottawa sand deposit with $40 \%$ relative density in the UB-NEES laminar box. This sand placement method allows sand grains to sink slowly through water, like natural alluvial deposition of sands in rivers or lakes. As illustrated in Figure 4, the deposition process involves the following steps: (1) the membrane is placed inside the box and filled with water to a depth of about $30 \mathrm{~cm}$; (2) soil and water mixture from $.42 \mathrm{~m}^{3}$ soil storage box is pumped by a slurry pump with $2 \mathrm{~cm}$ diameter flexible slurry hose to uniformly place sand throughout the laminar box; (3) at the same time, a water pump is used to return the excess water from the laminar box back to the soil storage box. This closed-loop pumping system is adjusted to maintain average $30 \mathrm{~cm}$ height of water above the sand surface inside the laminar box to achieve the loose deposition. The top $30 \mathrm{~cm}$ of the soil inside the box is found to be slightly denser than the soil at the bottom, due to the limitation of maintaining the $30 \mathrm{~cm}$ water near the top of the box.

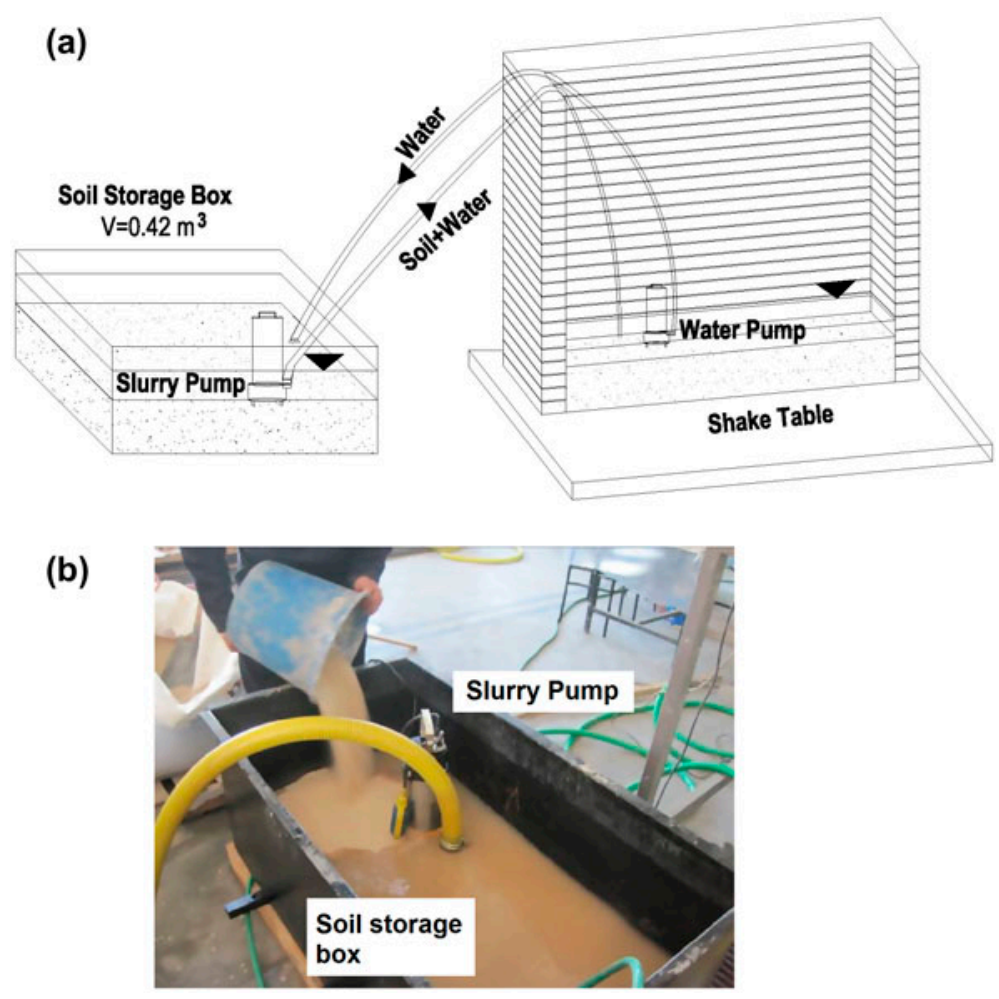

Figure 4. Hydraulic filling: (a) schematic view; and (b) sample preparation. 


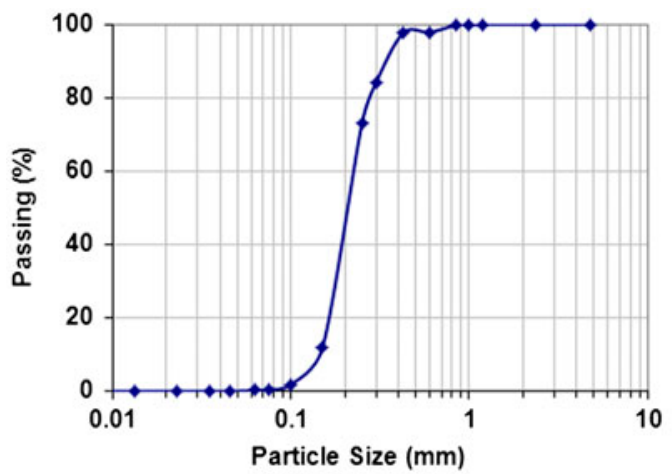

\begin{tabular}{|cc|}
\hline Parameters & Values \\
\hline $\mathrm{G}_{\mathrm{s}}$ & 2.61 \\
\hline $\mathrm{e}_{\max }$ & 0.79 \\
\hline $\mathrm{e}_{\min }$ & 0.60 \\
\hline $\mathrm{D}_{10}(\mathrm{~mm})$ & 0.12 \\
\hline $\mathrm{D}_{30}(\mathrm{~mm})$ & 0.18 \\
\hline $\mathrm{D}_{50}(\mathrm{~mm})$ & 0.21 \\
\hline $\mathrm{C}_{\mathrm{u}}$ & 1.17 \\
\hline $\mathrm{C}_{\mathrm{c}}$ & 1.29 \\
\hline
\end{tabular}

Note: $G, m$ Specific gravity (ASTM D8S4), $e_{\operatorname{mim}}=$ minimum void rati (ASTM D42S4), $e_{\max }=$ maximum void ratio (ASTM D4253), $D_{10}: 10 \%$ finer, $D_{30}: 30 \%$ finer, $D_{00}: 50 \%$ finer $C_{3}=D_{60} / D_{10}$ and $C_{6}=D_{30}^{2} /\left(D_{10} D_{60}\right)$

Figure 5. Basic properties and sieve analyses of sand used in the shake table tests.

The soil used for the shaking table tests is the sub-rounded shape fine silica sand supplied locally, with basic properties and grain size distribution displayed in Figure 5. It is defined as poorly graded sand (SP) according to the unified soil classification system. The saturated unit weight of the soil is measured by $10 \mathrm{~cm}$ diameter and $7 \mathrm{~cm}$ high cylindrical steel buckets. They are placed inside the laminar box at six different depths during the hydraulic filling process, and then removed when the buckets are filled with the sample. The average unit weight of the prepared sample ranges from $17-19 \mathrm{kN} / \mathrm{m}^{3}$ throughout the depth, with an average for the entire deposit close to $18 \mathrm{kN} / \mathrm{m}^{3}$. It takes about $9 \mathrm{~h}$ to fill the $1.4 \mathrm{~m}$ deep soil model inside the box.

\subsection{Cone penetration system}

The piezocone penetration tests $(\mathrm{CPTu})$ are conducted to estimate the relative density of the sand prior to each shaking tests along the depth. As displayed in Figure 6(a) and

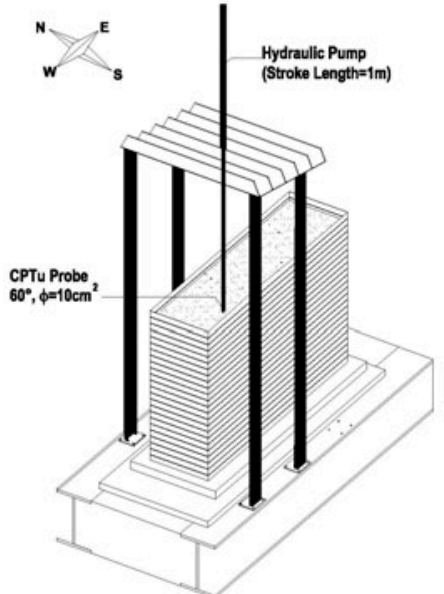

(a)

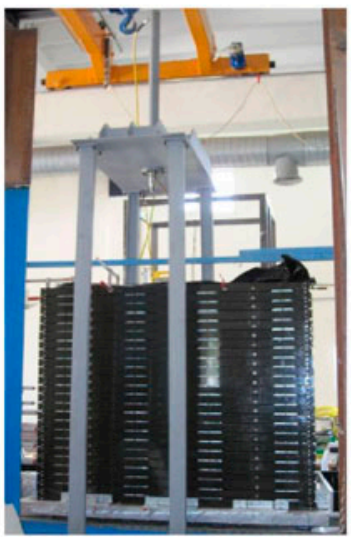

(b)

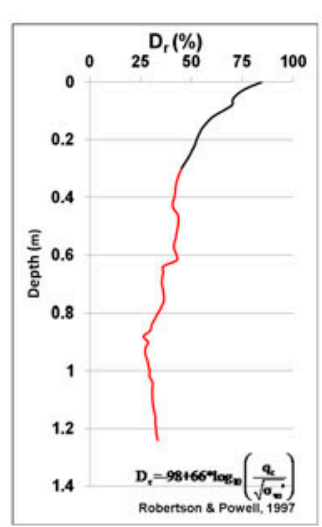

(c)

Figure 6. (a) Schematic view of the cone penetration system; (b) photo of the CPT system; and (c) Estimated relative density change with depth from CPTu test results. 
(b), the cone penetration system with maximum plumper cylinder capacity of $50 \mathrm{kN}$ and stroke length of $1 \mathrm{~m}$ is used to advance $60^{\circ}$ tapered, $10 \mathrm{~cm}^{2}$ tip area cone (diameter of $3.57 \mathrm{~cm}$ ) into the soil at one location at a constant penetration speed of $2 \mathrm{~cm} / \mathrm{s}$ (ASTM D3441). The nova acoustic CPTu device used in this study is manufactured by Geotech Inc., Sweden. CPTu tests provide measurements of cone penetration resistance $\left(q_{c}\right)$, friction resistance $\left(f_{s}\right)$ and pore water pressure $\left(u_{2}\right)$ values along the depth. The relative density values are estimated from the measured cone penetration resistance by using the empirical relationship given by Lunne, Robertson, and Powell (1997).

$$
D_{r}=-98+66 \times \log _{10}\left(\frac{q_{c}}{\sqrt{\sigma_{v o}^{\prime}}}\right)
$$

where $D_{r}=$ relative density in percentage; $\sigma_{v o}{ }^{\prime}=$ effective vertical stress in the same units as that of measured cone penetration resistance, $q_{c}$. Figure $6(\mathrm{c})$ shows the variation of relative density with depth right after the deposition. As illustrated in the figure, after the preparation of the model (before $1 \mathrm{st}$ shake test) below $.3 \mathrm{~m}$ depth, the initial relative density is ranged from 30 to $40 \%$ with an average for the whole deposit close to $34 \%$. This range is also consistent with relative densities measured immediately after the deposition of clean sand by hydraulic filling method (Mitchell, 1988; Poulos \& Hed, 1973; Thevanayagam et al., 2009; Whitman, 1970). The relative density measurements indicate that the uniformity of the deposit is achieved fairly good by the preparation method used in this study. The measured average value of the initial relative density is representative for many of the most liquefiable and artificial sand deposits observed in the field.

\section{Shaking table tests}

In order to understand the behaviour of the laminar box-soil response at different intensities, the soil deposit is subjected to four individual shaking tests (Table 1). Selection of the appropriate input accelerations to be used for the laminar box liquefaction tests have to be large enough to induce liquefaction during the shaking table tests. One way to define the peak ground accelerations (PGA) of the shakings is to look at field evidences and calculations related to soil accelerations and liquefaction or pore water

Table 1. Summary of the shaking table and CPTu tests.

\begin{tabular}{|c|c|c|c|c|c|c|c|}
\hline Test name & $\begin{array}{c}\text { Average } \\
\text { initial } \\
D_{r}(\%)\end{array}$ & $e$ & $\begin{array}{c}\text { Frequency } \\
(\mathrm{Hz})\end{array}$ & $\begin{array}{l}\text { Input max. } \\
\text { diplacement } \\
(\mathrm{mm})\end{array}$ & PGA (g) & $\begin{array}{c}(\mathrm{PGA})_{\mathrm{eq}} \\
(\mathrm{g})\end{array}$ & $\begin{array}{c}\text { Duration } \\
(\mathrm{sec})\end{array}$ \\
\hline CPTu_0 & 34 & .73 & - & - & - & & \\
\hline Ist shake & & & 2 & \pm 3.41 & .05 & .08 & 12 \\
\hline CPTu 1 & 51 & .69 & - & - & - & - & - \\
\hline 2nd shake & & & 2 & \pm 6.83 & .11 & .17 & 12 \\
\hline CPTu_2 & 56 & .68 & - & - & - & - & - \\
\hline 3rd shake & & & 2 & \pm 30 & .48 & .74 & 12 \\
\hline CPTu_3 & 62 & .67 & - & - & - & - & - \\
\hline 4th shake & & & 2 & \pm 35 & .56 & .86 & 12 \\
\hline CPTu_4 & 74 & .65 & - & - & - & & - \\
\hline
\end{tabular}

Notes: Average initial $D_{r}=$ average relative density each shake test, e = void ratio, PGA = peak ground acceleration, CPTu $0=$ CPT test before the first shaking test, CPTu_1 $=$ CPT test before the second shaking test, CPTu_2 $=$ CPT test before the third shaking test, CPTu_3 $=$ CPT test before the fourth shaking test, CPTu_4 $=$ test after the fourth shaking test. 
pressure build-up. The table of case histories of liquefaction indicates that the lowest value of PGA in the field causing initial liquefaction has been equal to $.12 \mathrm{~g}$. From the previous earthquake records, it is also found that the predominant frequency of most of the earthquakes that cause severe damages were in the range of $1-2 \mathrm{~Hz}$, and PGA was around $.5 \mathrm{~g}$. With these considerations in mind, the test sequence and levels of shaking conducted on the saturated sand in the laminar box are 24 cycles of $2 \mathrm{~Hz}$ sine wave shaking with PGA of .05, .11, .48 and $.56 \mathrm{~g}$, respectively. Seed and Idriss (1971) argued that laboratory experiments using the sine wave excitation of soils are considered to be more severe than real earthquakes. Hence, PGA used for the sine wave-based laboratory experiments should be scaled up by a factor of $1 / .65$ while making predictions of soil response for real earthquakes.

Before application of the each shake, amount of densification is estimated from the $\mathrm{CPTu}$ tests. In Table 1, the notation "CPTu_0" refers to CPTu test conducted at one location right after the deposition. The average relative density is increased from 34 to $51 \%$ after the first shake, $56 \%$ after the second shake, $62 \%$ after the third shake and $74 \%$ after the fourth shake. After each shaking, the generated excess pore pressure is allowed to dissipate entirely in more than two hours. In order to evaluate the performance of the laminar box as well as the acceleration, pore water pressure, vertical and horizontal displacements of the soil during the shaking, the instruments are placed inside the soil, outside of the laminate walls and on the shake table as shown in Figure 7 (a). The instrumentation on the laminar box includes seven potentiometers for horizontal displacement measurements, eight uniaxial accelerometers for acceleration measurements at various depths on the laminates and one on the shake table. The instrumentation within the soil model includes three submersible uniaxial accelerometers for measuring the accelerations and five piezometers for measuring the pore water pressure at different depths. KPC-500 kPa-type piezometers with $30 \mathrm{~mm}$ diameter ceramic filter are used. The instruments within the soil specimens are positioned inside the laminar box vertically before the hydraulic filling by hanging the instruments from a wooden frame located above the laminar box. The attachment to the wooden frame is cut when the box is filled with soil, prior to the shaking tests. In addition, two potentiometers are used on the sand surface to measure the surface settlements during and after the dynamic-based excitations. The extension rod end of each potentiometer is connected to the plate which is laid horizontally on the sand surface. The density of the plate is chosen as liquefied soil to allow the plate settle with the soil and prevent it from sinking or floating during testing. Figure 7 (b) shows the layout of the different types of instruments on the laminar box and within the soil. The data have been recorded with a common reference time frame and time interval by using the data acquisition system of 47 numbers of channels.

\subsection{Performance of the shake table and sensor reliability}

The full weight of the laminar box, including the membrane and the soil inside it at its total capacity, is about $2560 \mathrm{~kg}$. The performance of the shake table is monitored by comparing the base input accelerations to the base excitations verified by accelerometer mounted on the shake table for each test as shown in Figure $8(a-d)$. There is an excellent agreement between the measured and excited motion at the base. These test results indicate that the shake table system is essentially functioning well for different shaking amplitudes. 


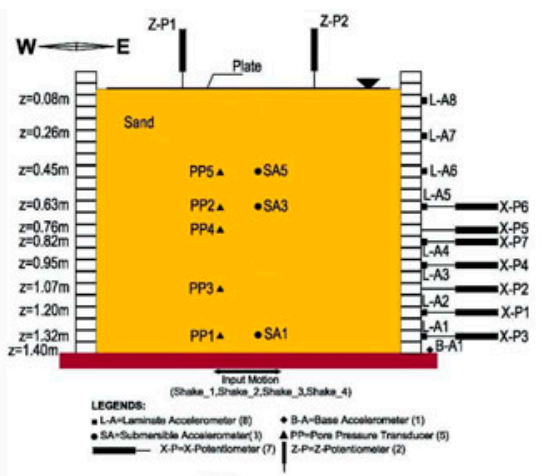

(a)

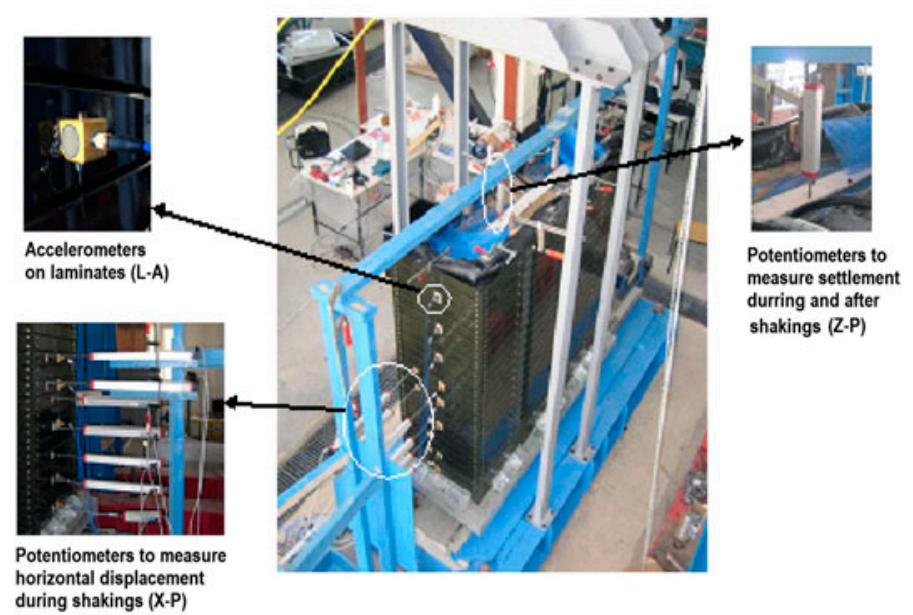

(b)

Figure 7. Instrumentations: (a) Schematic north view of model and instrumentations; and (b) Photo of wooden frame and instruments.

The reliability of the sensor data is illustrated using cross-comparison of measured data by different types of sensors. The accelerations measured by accelerometers attached to the same laminates are compared by double differentiating the displacements measured by potentiometers. As an example, the comparisons at $.82 \mathrm{~m}$ depth during four shaking tests are displayed in Figure 9. It depicts that the lateral displacement information obtained from all measurements gives consistent results of the laminate movements. Hence, the measurements by these sensors are compatible and can be used together for the analysis of the laminar box and the soil response under shaking with a high degree of confidence.

\section{2. $\quad$ Numerical modelling}

The calibrated numerical model UBCSAND (Beaty \& Byrne, 2011), which represents the cyclic soil response including liquefaction, is incorporated into the dynamic coupled stress-flow finite difference programme FLAC (Itasca Consulting Group, 2009) in order 


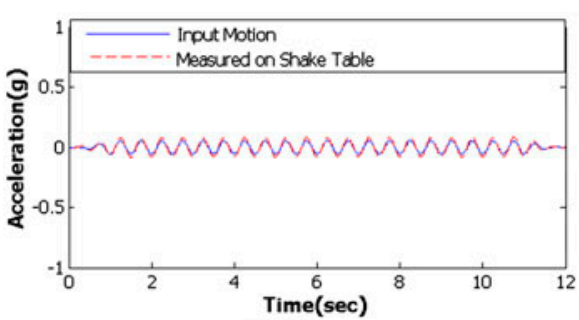

(a)

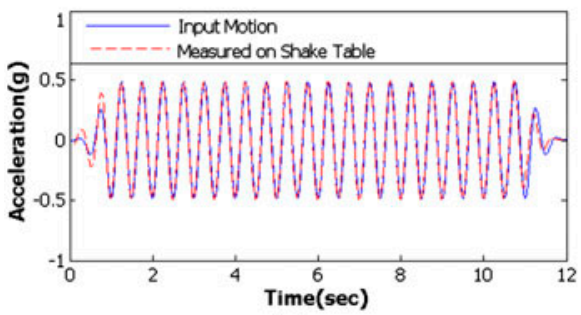

(c)

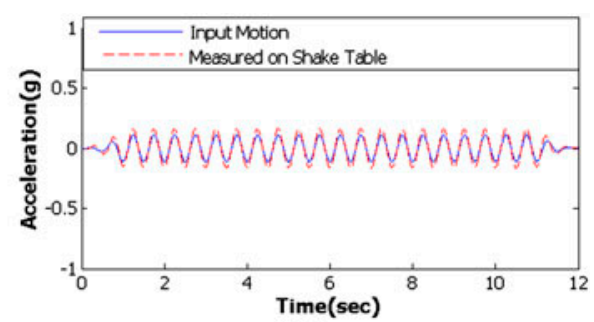

(b)

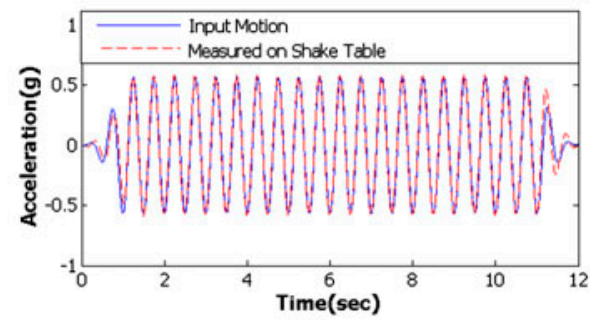

(d)

Figure 8. Base input acceleration and measured acceleration time histories on shake table in the longitudinal direction, (a) first shake; (b) second shake; (c) third shake; and d) fourth shake.

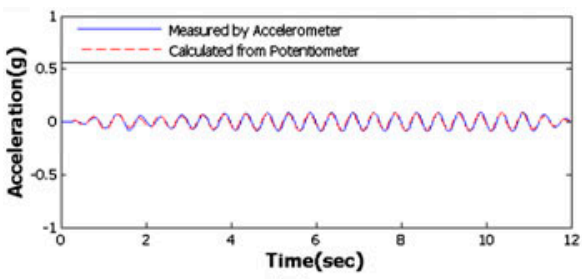

(a)

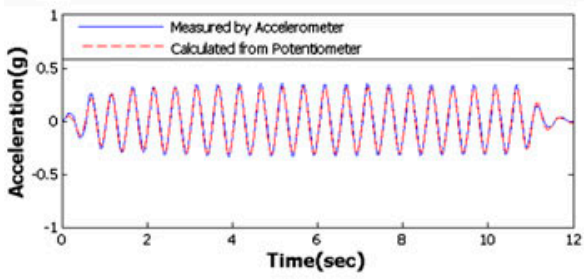

(c)

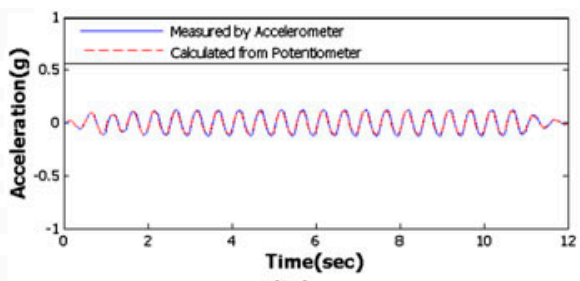

(b)

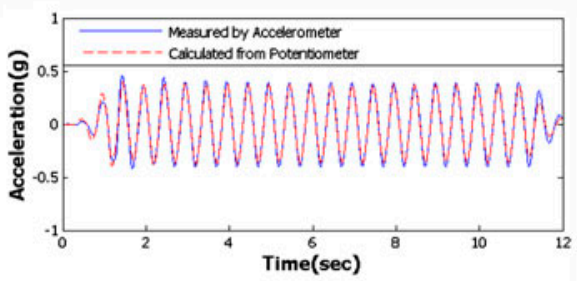

(d)

Figure 9. Cross-comparison of laminate (L10) movement measured by accelerometer (LA-4) and potentiometer (XP-7) during the, (a) first shake; (b) second shake; (c) third shake; and d) fourth shake.

to compute the free-field response of the model and also to have a better insight in the performance of the laminar box. The reasonable predictions of acceleration and pore pressure response for the free-field can be obtained by this model (Beaty and Byrne, 1998, 2011; Byrne et al., 2004; Puebla et al., 1997). Figure 10 illustrates the cross-section of the shake table model which shows the locations of the pore pressure transducers, potentiometers and accelerations together with the FLAC computational 
(a)

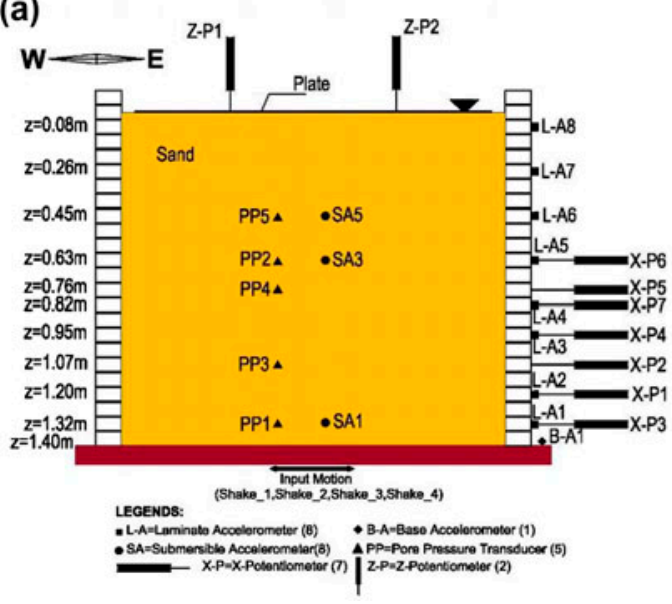

(b)

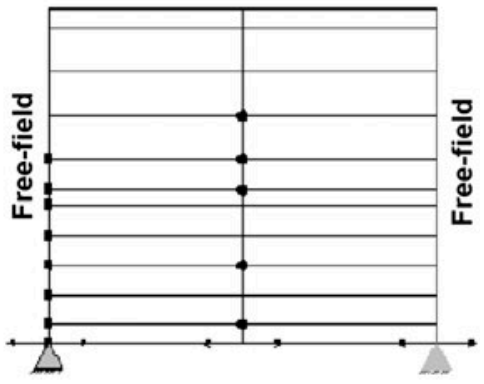

Figure 10. (a) Shake table model; and (b) FLAC model recording points.

model. As shown in Figure 10(b), the $1.4 \mathrm{~m}$ height soil model is simulated in FLAC with 2 columns of elements and 11 individual layers. The vertical boundaries of each layer are attached to each other what allows differential displacements in the vertical direction, but not in the horizontal.

The appropriate input parameters for the model can be obtained directly from the cyclic test data, or indirectly from field experience with similar soils during past earthquakes. The common practice is the indirect approach with liquefaction response expressed in terms of penetration resistance, and this approach is used in this study. The UBCSAND model has been calibrated to reproduce the Youd et al. (2001) liquefaction screening chart which in turn is created on field observations during past earthquakes and is expressed in terms of standard penetration test resistance, $\left(\mathrm{N}_{1}\right)_{60}$. The model properties are, therefore, expressed in terms of $\left(\mathrm{N}_{1}\right)_{60}$ which are determined from the known relative density upon an approximate conversion, such as that proposed by Skempton (1986). In the UBCSAND model, the elastic behaviour is expressed in terms of shear modulus $\left(G^{e}\right)$ and bulk $\left(B^{e}\right)$ modulus which are stress-level dependent (Beaty \& Byrne, 2011);

$$
\begin{aligned}
& B^{e}=K_{B}^{\mathrm{e}} \times P_{a} \times\left(\frac{\sigma_{m} \prime}{P_{a}}\right)^{0.5} \\
& G^{e}=K_{G}^{e} \times P_{a} \times\left(\frac{\sigma_{m} \prime}{P_{a}}\right)^{0.5}
\end{aligned}
$$

where $K_{B}{ }^{e}$ and $K_{G}{ }^{e}$ are modulus numbers, $P_{a}$ is the atmospheric pressure and $\sigma_{m}{ }^{\prime}$ is the initial mean effective stress. For each shaking test, the elastic shear moduli are estimated using the Seed, Wong, Idriss, and Tokimatsu (1986) relationship;

$$
G^{e}=4382 \times\left(\mathrm{N}_{1}\right)_{60}^{0.333} \times\left(\sigma_{m}\right)^{0.5}
$$

where, $G^{e}$ and $\sigma_{m}{ }^{\prime}$ are in $\mathrm{kPa}$. The shear moduli number of soil is evaluated for different relative densities by using the Equations 4 and 5 . The bulk moduli number is 
determined from the shear moduli number and described by the following relation (Beaty \& Byrne, 2011);

$$
K_{B}^{e}=\alpha K_{G}^{e}
$$

in which $\alpha$ depends on the elastic Poisson's ratio. In order to estimate the appropriate value for the bulk modulus, two consolidated drained triaxial tests are conducted on sand having 35\% relative density. These loose sand samples are prepared by tamping method under the moist conditions to assess the stiffness of the soil. The stress-strain behaviour of the soil for initial vertical stress of 100 and $200 \mathrm{kPa}$ is shown in Figure 11 (a). From these test results and Equation 3, the bulk modulus number is found as 456. Alfa, which is the ratio of the bulk modulus number to shear modulus number, is calculated as .54 . The equation to find the plastic shear moduli $\left(G^{p}\right)$ is given by (Beaty \& Byrne, 2011);

$$
G^{p}=G_{i}^{p}\left(1-\frac{\left(\tau / \sigma_{m} \prime\right)}{\sin \phi_{f}} R_{f}\right)^{2}
$$

where $R_{f}$ is the failure ratio used to prevent the over-prediction of strength at failure. $R_{f}$ varies between .7 and .98 and decreases with an increase in the relative density (Beaty $\&$ Byrne, 2011). $G_{i}^{p}$ is the plastic modulus at low level of stress ratio, and it is approximated through the relationship $G_{i}^{p} \approx 3.7 \times D_{r}^{4} \times G^{e}+P_{a}$ (Byrne et al., 2004). $\phi_{f}$ is the peak friction angle which changes with constant volume friction angle $(\phi)$ and relative density. The friction angle of this sand is determined from the drained triaxial test data as shown in Figure 11(b). It is derived from the Mohr-Coulomb failure criterion and equals to $36^{\circ}$. This friction angle value is consistent with the value measured for similar soils (Koloski et al., 1989). The properties of the sand for each shaking test are listed in Table 2, in order to provide the basis for comparison of the measured data.

The first analysis step is to install equilibrium stresses and pore pressures into the soil to establish a reasonable initial stress state before dynamic simulations. The gravity does not have a significant role in the sand-placement method used in this study. Thus, the initial horizontal effective stress is selected as .7 times the vertical effective stress. The dynamic analysis is then performed after specifying dynamic material properties,

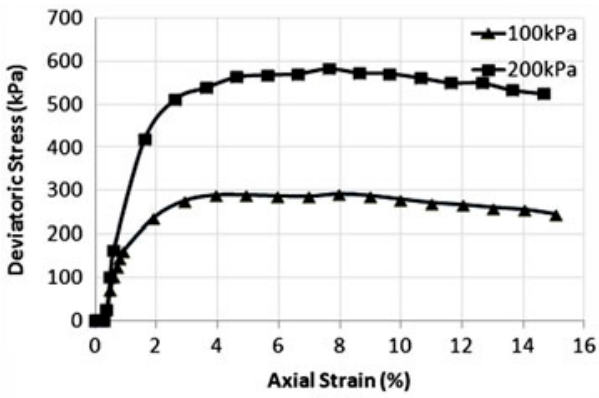

(a)

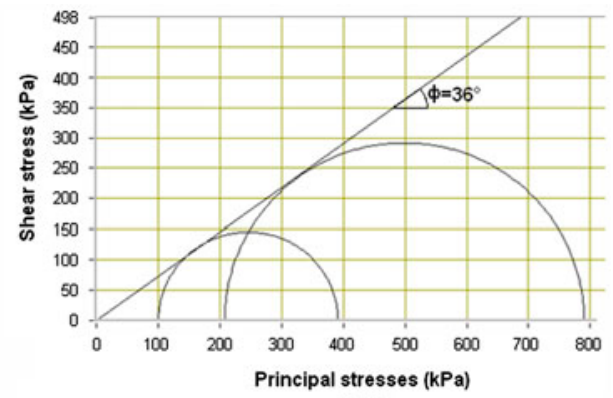

(b)

Figure 11. Results of consolidated drained triaxial test conducted for sand having $35 \%$ relative density. 
Table 2. Properties of the soil used in the numerical simulations.

\begin{tabular}{lcccccc}
\hline Shaking number & $D_{r}(\%)$ & $\left(N_{1}\right)_{60}$ & $K_{\mathrm{B}}{ }^{e}(\mathrm{kPa})$ & $K_{\mathrm{G}}{ }^{e}(\mathrm{kPa})$ & $\phi_{f}\left({ }^{\circ}\right)$ & $R_{f}$ \\
\hline 1st Shake & 34 & 7 & 453 & 838 & 36.7 & .82 \\
2nd Shake & 51 & 11 & 526 & 974 & 37.1 & .77 \\
3rd Shake & 58 & 14 & 570 & 1055 & 37.4 & .74 \\
4th Shake & 62 & 16 & 596 & 1103 & 37.8 & .73 \\
\hline
\end{tabular}

Note: $D_{r}=$ relative density, $\left(\mathrm{N}_{1}\right)_{60}=$ normalised standard penetration resistance, $K_{\mathrm{B}}{ }^{e}=$ elastic bulk modulus number, $\phi_{f}=$ peak function angle, $R_{f}=$ failur ratio.

applying compliant boundary conditions (quiet boundary) to the base, adopting free-field conditions to the lateral boundaries and specifying the input motions given in Figure 8 to the base of the model.

\subsection{Comparison of shake table measurements with 2D-FLAC model}

Figure 12(a) shows the lateral displacements computed by the numerical analysis and Figure 12(b) shows the lateral displacements recorded by the potentiometers located during four amplitudes of shaking at the fifth cycle from the depth of .6-1.3 m. During each shaking test, the soil mass deforms in almost linear, simple shear mode from the box base to the depth of $.8 \mathrm{~m}$ then deforms in a non-linear, irregular mode from the depth of .8-.6m. This linear behaviour at the bottom of the box is also observed from the level ground liquefaction tests conducted in the laminar box by McManus Turner, and Charton (2005) and Thevanayagam et al. (2009). As expected, due to the increase of the maximum input accelerations, the lateral displacements are also increased. The measured lateral displacements are found to be slightly higher than the computed displacements during the first and second shaking tests. The computed horizontal displacement patterns of the third and fourth shaking test results are similar to the measured third and fourth shaking test results, respectively. The reason for computing relatively small lateral displacements during the low shaking amplitude (first and second shaking)

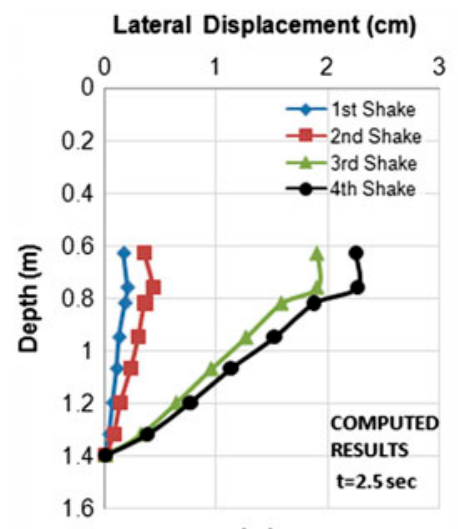

(a)

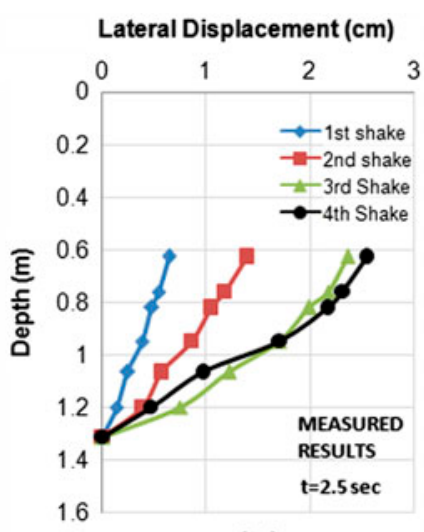

(b)

Figure 12. Lateral displacement profiles from $.6 \mathrm{~m}$ to $1.3 \mathrm{~m}$ at fifth cycle: (a) computed from FLAC; and (b) recorded by potentiometers attached to the laminates. 
tests can be due to the hyperbolic equation which estimates the relationship between shear stress and the plastic shear strain. At low values of shear stresses, this equation may cause a minor error, particularly since the hyperbola is only an approximate relationship for the linear elastic and hyperbolic plastic response.

The surface settlement during the first shaking is observed by using a settlement plate connected with two vertically placed potentiometers. Total vertical strain $\left(\varepsilon_{v}\right)$ of approximately $3.7 \%$ is measured as a result of the first shaking test. Approximately $1 \%$ vertical strain occurred during the shaking, and the rest $(2.7 \%)$ as the result of the pore pressure dissipation. Figure 13 presents the settlement time histories measured at one of the vertically placed potentiometer (ZP-2) and computed by the numerical analysis. Overall, during the first shaking, there is a good agreement between the computed and measured settlements. The magnitudes of net vertical strains observed in this study are also compatible with strains measured at the field sites of level ground liquefaction, as well as measured in laboratory element tests (Ishihara \& Yoshimine, 1996; Tokimatsu $\&$ Seed, 1987). The surface settlements during the second, third and fourth shaking tests are not measured by vertically placed potentiometers. However, they are measured manually. For the second, third and fourth shaking tests, the net vertical strains are determined as $3.2,2.5$ and $2 \%$, respectively.

The accelerations and excess pore pressures measured within the soil and computed by the numerical analysis are compared in order to estimate the free-field response during the shaking tests. Figure 14 presents the acceleration time histories of measured and calculated accelerations at depths of $.45, .63$ and $1.32 \mathrm{~m}$. As depicted in the figure, the liquefaction occurred mostly at the same time. Barring some minor differences, the calculated maximum initial accelerations are in general agreement with the measured maximum initial accelerations before liquefaction. The large reduction in acceleration amplitude with time is estimated from the numerical analysis, whereas the accelerations measured within the soil decrease slightly after the liquefaction. This reduction in acceleration amplitude might be due to the impulsive loss of shear stiffness of the soil in the laminar box when liquefaction occurs. These results indicate that, after the event of the liquefaction, the measured results might not be accurate, hence may not represent the real motions of the soil, due to the rotation of the sensors inside the soil at this stage. Also, due to high increase of pore water pressure, the water-sealed sensors may get wet, and the acceleration results may not be precise at this phase. Thus, for the subsequent shaking tests, the measured acceleration time histories are not compared with the computed acceleration time histories.

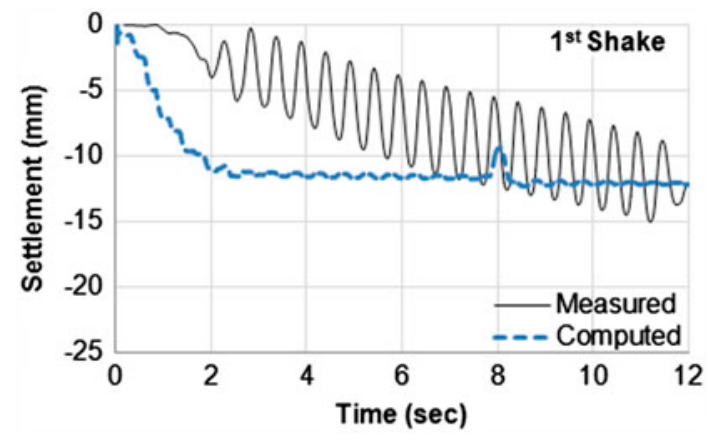

Figure 13. Measured and computed settlement histories during the first shaking test. 

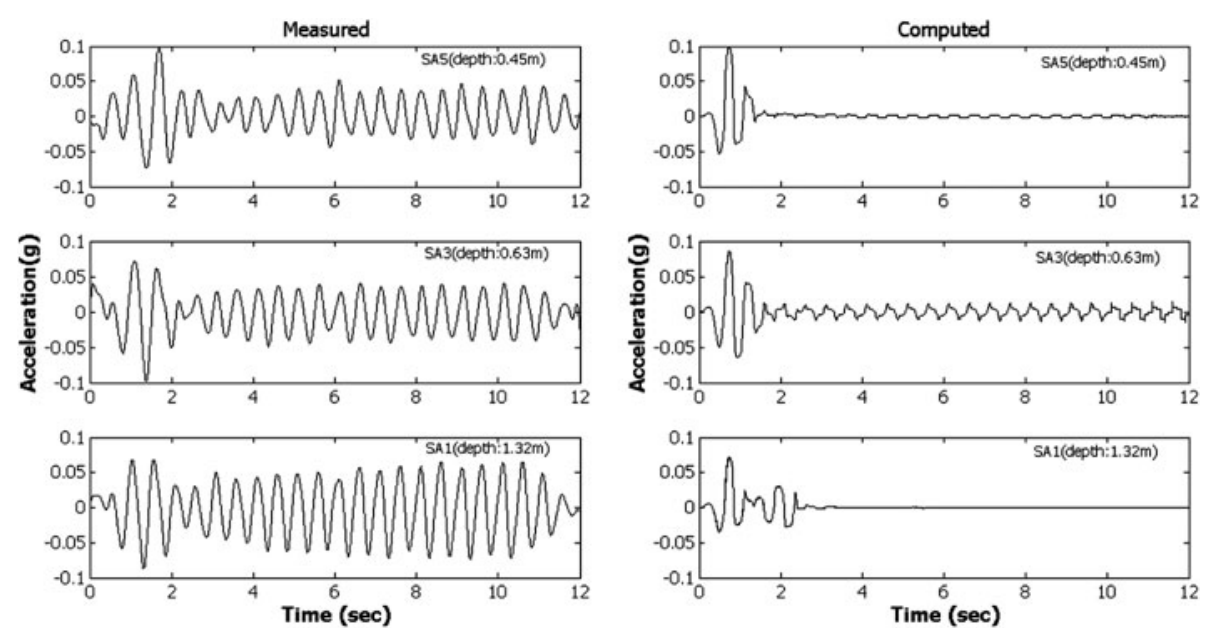

Figure 14. Measured (left) and computed (right) acceleration time histories from 1st shaking test and numerical model.

Figure 15 presents the measured and computed excess pore water pressure time histories during the four shaking tests at depths of $.45, .63, .76,1.07$ and $1.32 \mathrm{~m}$. As illustrated in the figure, for each shaking tests, the excess pore pressure is increased with the increase in the cycles of shaking at a linear rate throughout the entire sand deposit until liquefaction is triggered at each depth. In general, liquefaction often occurs when the excess pore water pressure $(\Delta u)$ reaches the initial vertical effective stress $\left(\sigma_{v 0}{ }^{\prime}\right)$ corresponding to the pore pressure ratio $\left(r_{u}=\Delta u / \sigma_{v 0}{ }^{\prime}\right)$ of one. The traditional definition of $r_{u}$ shows large fluctuations during the cyclic loading that may not be related to the liquefaction. Because of the permanent changes in total stress, the peak value of $r_{u}$ corresponding to a liquefied height might be remarkably different from one. For the undrained saturated sands, liquefaction usually occurs when the normalised excess pore pressure is lower than one. Hence, for each shaking, the liquefaction triggering procedures are evaluated when the excess pore water pressure has reached the initial vertical effective stress corresponding to $90-95 \%$ pore pressures rise. In contrast to the acceleration time histories, overall the computed excess pore pressures are in good agreement with the measured values. However, for each shaking, at depth of $0.45 \mathrm{~m}$, constantly the computed excess pore pressure results are not matching the recorded data. This might be due to the dislocation of the pore pressure transducers during the preparation process of the model. The arrows in the figure are used to illustrate the instant of liquefaction triggering. The time for the first shaking to reach liquefaction in the laminar box is in good correlation with the change in the acceleration pattern. The measurements and computed results show that the liquefaction at each test occurs more or less at the same time throughout the depth. This happens due to the almost constant relative density before each shaking test from .3 to $1.3 \mathrm{~m}$ depth. As shown in the figure, although the increase in relative density from the first shake to the second shake is $17 \%$ (34 to $51 \%$ ), the number of cycles required to cause liquefaction during the second shaking is found to be slightly smaller than the first shaking. The increase in relative density from the first shake to the third shake is of $22 \%$ (34 to $56 \%$ ). The number of cycles required to cause liquefaction during the third shaking at the top half of the box is found to be slightly larger than during the second shaking. Also, the liquefaction is not observed at 


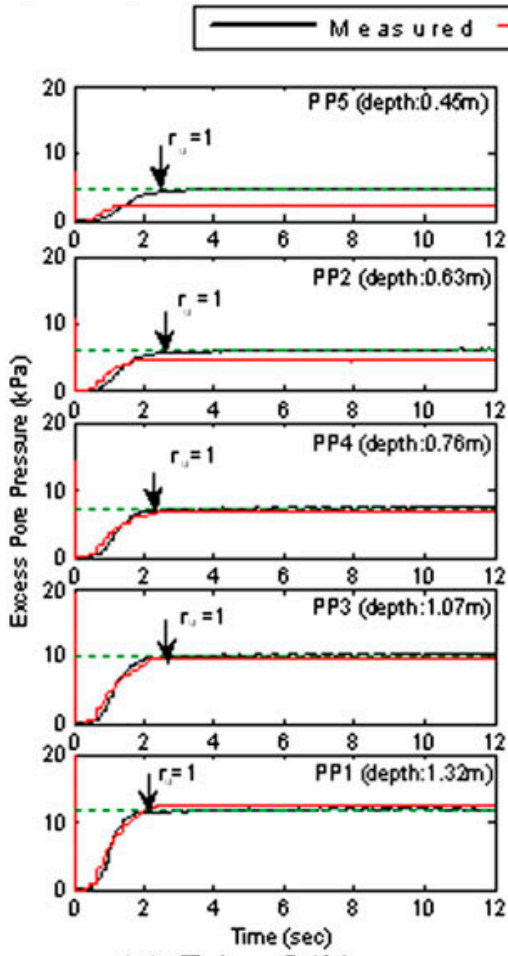

(a) $\left(D_{Y}\right)_{\text {iri }}=34 \%$

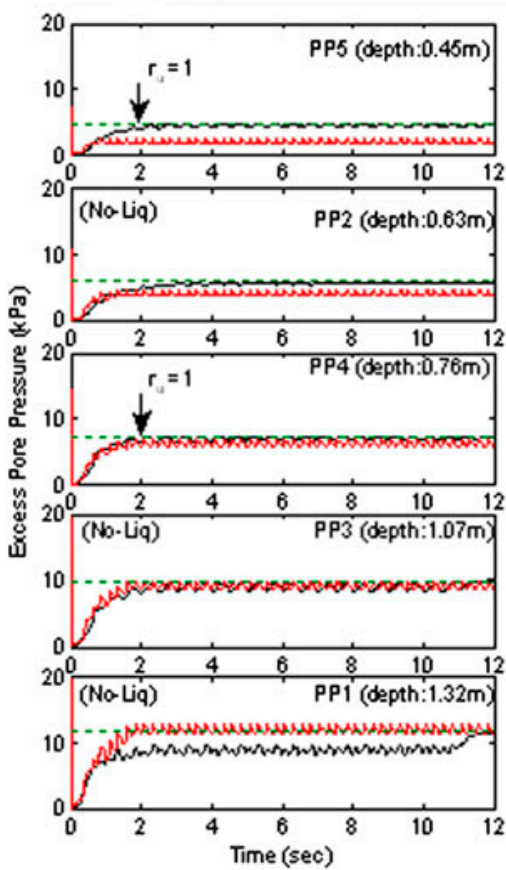

(c) $\left(D_{Y}\right)_{\text {iri }}=56 \%$

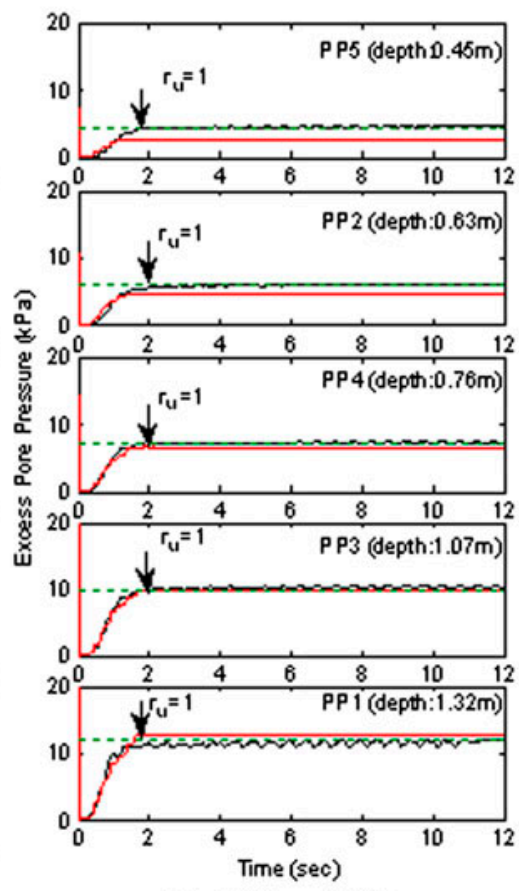

(b) $\left(D_{x}\right)_{\text {ini }}=51 \%$

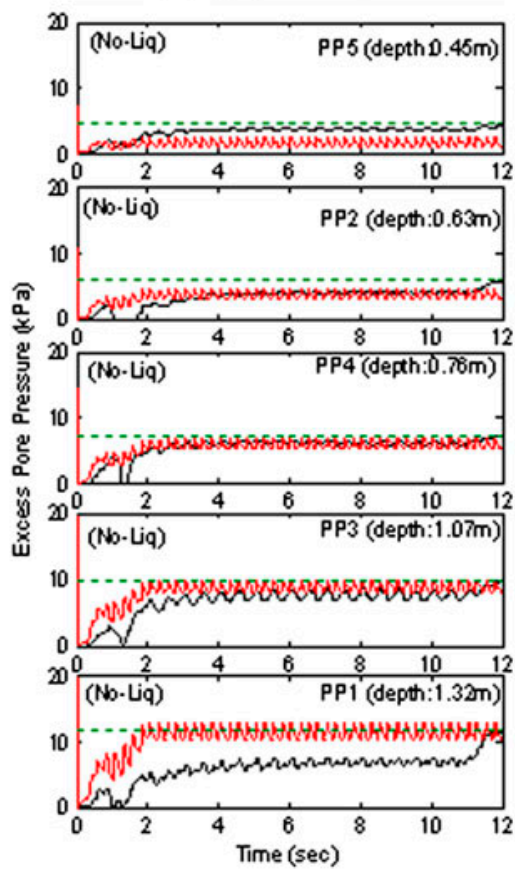

(d) $\left(D_{\mathrm{r}}\right)_{\text {ini }}=62 \%$

Figure 15. Measured and computed excess pore pressure time histories during (a) first Shake; (b) second Shake; (c) third Shake; and (d) fourth Shake. 
the bottom half of the laminar box. The increase in relative density from the first shake to the fourth shake is of $28 \%(34-62 \%)$. The liquefaction is not observed at any depth during the fourth dynamic base excitation. These subsequent shaking test results show the number of cycles in order to cause liquefaction; hence, the liquefaction resistance only increases when the increase in relative density is about $22 \%$. These findings from the present study are compatible with the research of Mesri, Feng, and Benak (1990). They also suggested that the liquefaction resistance may increase after the increase of the relative density on the order of $20-30 \%$.

\section{Conclusion}

A 1-g model testing system is presented in this paper in order to simulate the liquefaction of loose to medium dense saturated sands under 1D shake table tests. The system is composed of 1D laminar box, cone penetration system, soil model, system for hydraulic soil pumping, instrumentation and related testing hardware. In this paper, first, results of the shake table performance tests, static calibration tests of the box without the sand deposit, shaking table tests and piezocone penetration tests for consideration of the sample preparation are presented. Second, the measured shake table model responses are compared with the numerical simulations using the calibrated UBCSAND model (version 904aR). Based on these test results, the following features can be summarised as follows:

(1) The static pull out tests show that the friction between the rollers and the laminates are exceptionally small. Based on this static calibration test, the loading environment is found similar to the free-field loading conditions.

(2) The soil sample is prepared by the hydraulic filling method. The uniformity and density of the soil specimen prepared inside the box with this method is found satisfactory to prepare loose sand deposits which are prone to liquefaction.

(3) The instruments installed within the laminates can also obtain reliable measurements of the box movements. The recorded data obtained from the different instruments at the same locations are corroborated each other extremely well. Such an agreement of comparisons of accelerations and displacements obtained from different types of sensors indicates that the recordings are of high quality and capture the actual response of the laminar box.

(4) The horizontal laminate displacements are compared with the lateral displacements computed from the previously calibrated numerical model UBCSAND. As expected, due to the increase in the maximum input accelerations, the lateral displacements are also increased. The measured lateral displacements are found to be slightly higher than the computed displacements during the first and second shaking tests. For the simple UBCSAND model, at low values of shear stresses, the hyperbolic relationship causes a minor error mostly since the hyperbola is only an approximate relationship for the linear elastic and hyperbolic plastic response. This can be the reason for computing the small lateral displacements at low shaking intensities.

(5) The surface settlement recorded during the first shaking is compared with the computed settlement using the numerical model UBCSAND. Overall, a good agreement is found between the computed and measured settlements.

(6) The numerically computed excess pore pressures and accelerations for different depths are compared with the measurements. The calculated maximum initial 
accelerations are in general agreement with the measurements before liquefaction. However, after liquefaction, it is not certain whether the measured movements can represent the real motions of the soil inside the soil at this stage due to some recording issues of the accelerometers. In contrast to the acceleration time, overall the computed excess pore pressures are in a good agreement with the measured values.

(7) The measurements and computed results show that the liquefaction at each test occurs more or less at the same time throughout the depth.

The above-mentioned results show that the response of the soil is essentially that of a shear beam simulating the free-field conditions and the effectiveness of the laminar box system for shaking table tests is satisfactory for dynamic model tests in 1-g gravity. Moreover, it is also concluded that the number of cycles required to cause liquefaction do not increase when the increase in relative density from initial shake to subsequent shake is less than $22 \%$.

\section{Acknowledgements}

This study was supported by the European Union Marie Curie Fellowship under Grant No. IRG248218 and TUBITAK Project No: 111M435. These supports are gratefully acknowledged. The authors wish to thank Assitant Prof. Gursoy Turan and Assitant Prof. Selcuk Saatci for their creative contributions and Research Assistants Irem Kahraman and Mustafa Karaman for their assistance in conducting tests on the shaking table.

\section{References}

Abdoun, T., Dobry, R., O’Rourke, T. D., \& Goh, S. H. (2003). Pile response to lateral spreads: Centrifuge modeling. Journal of Geotechnical and Geoenvironmental Engineering, 129, 869-878.

Arulanandan, K., \& Scott, R. F. (1993). Verification of numerical procedures for the analysis of soil liquefaction problems. Proceedings of the International Conference on the verification of numerical procedures for the analysis of soil liquefaction problems, Davis, California, USA.

ASTM. Designation D3441 - Standard test method for deep quasi-static, cone, and friction cone penetration tests of soil. In soil and rock: Building Stones. Annual Book of ASTM Standards, American Society for Testing and Materials, vol. 4.08, 1993.

Beaty, M. H., \& Byrne, P. M. (1998). An effective stress model for predicting liquefaction behaviour of sand. Proceedings of Specialty Conf., Geotechnical Earthquake Eng. and Soil Dynamics III, vol. 1, ASCE GSP no. 75, pp. 766-777.

Beaty, M. H., \& Byrne, P. M. (2011). UBCSAND constitutive model version 904aR, Documentation report. Retrieved from UBCSAND constitutive model on Itasca UDM website. http:// www.itascaudm.com/media/download/UBCSand/UBCSAND_UDM_Documentation.pdf

Byrne, P. M., Park, S., Beaty, M. H., Sharp, M., Gonzales, L., \& Abdoun, T. (2004). Numerical modelling of liquefaction and comparison with centrifuge tests. Canadian Geotechnical Journal, 41, 193-211.

Brandenberg, S. J., Boulanger, R. W., Kutter, B. L., \& Chang, D. (2005). Behaviour of pile foundations in laterally spreading ground during centrifuge tests. Journal of Geotechnical and Geoenvironmental Engineering, 131, 1378-1391.

Dobry, R., Taboada, V., \& Liu, L. (1995). Centrifuge modelling of liquefaction effects during earthquakes. Proceedings of the First International Conference on Earthq. Geotech. Eng. (ISTokyo), Keynote Lecture, Tokyo, Japan, A. A. Balkema, Rotterdam/Brookfield, 1291-1324.

Elgamal, A., \& Zeghal, M. (1992). Analysis of wildlife site liquefaction during the 1987 superstition hills earthquake (Rep. No. NCEER-92-O019). Proc. 4th U.S. Japan Workshop on Earthquake Resistant Des. of Lifeline Fac. and Countermeasures against Soil Liquefaction. In M. Hamada \& T. O'Rourke (Eds.), National Center for Earthquake Engineering Research (pp. 87-96). Buffalo, NY: SUNY at Buffalo. 
Elgamal, A., Zeghal, M., Taboada, V., \& Dobry, R. (1996). Analysis of site liquefaction and lateral spreading using centrifuge testing records. Soils and Foundations, 36, 111-121.

Fiegel G. L., Hudson M., Idriss I. M., Kutter B. L., \& Zeng X. (1994). Effect of model container on dynamic soil response. In C. F. Leung, F.-H. Lee, \& T. S. Tan (Eds.), Centrifuge 94 (pp. 145-150). Singapore: Balkema.

Haigh S. K., \& Madabhushi, S. P. G. (2005). The effect of pile flexibility on pile-loading in lateral spreading slopes. Geotechnical Special Publications, 145. In R. W. Boulanger \& K. Tokimatsu (Eds.), 2005, pp. 24-37.

Hamada, M., Yasuda, S., Isoyama, R., \& Emoto, K. (1986). Study on liquefaction induced permanent ground displacements. Japan: Research Report, Assn. for Development of Earthquake Prediction.

He, L., Elgamal, A., Abdoun, T., Abe, A., Dobry, R., Meneses, J., ... Tokimatsu, K. (2006). Lateral load on piles due to liquefaction-induced lateral spreading during $1 g$ shake table experiments. Proceedings of the Eighth US National Conference on Earthquake Eng., no. 881, San Francisco, EERI, Oakland, CA.

Ishihara, K., \& Yoshimine, M. (1996). Evaluation of settlements in sands following liquefaction during earthquakes. Soils Foundation, 32, 173-188.

Itasca Consulting Group. (1986). FLAC, fast lagrangian analysis of continua, version 6.0. Minneapolis, MN: Itasca Consulting Group.

Jafarzadeh, F. (2004). Design and evaluation concepts of laminar shear box for $1 \mathrm{~g}$ shaking table tests. 13th World Conference on Earthquake Eng., Vancouver, BC, Canada, p. 1391.

Koloski, J. W., Schwarz, S. D., \& Tubbs, D. W. (1989). Geotechnical properties of geologic materials. Washington Division of Geology and Earth Resources, Bulletin, 78, 19-26.

Lunne, T., Robertson, P. K., \& Powell, J. J. M. (1997). Cone penetration testing in geotechnical practice (p. 312). New York, NY: Blackie Academic, FF Spon/Routledge.

McManus, K. J., Turner, J. P., \& Charton, G. (2005). Inclined reinforcement to prevent soil liquefaction. Proceedings, Technical Conf., New Zealand Society for Earthquake Engineering, Wairakei, New Zealand, pp. 41-51.

Mesri, G., Feng, T. W., \& Benak, J. M. (1990). Post-densification penetration resistance of clean sands. Journal of Geotechnical Engineering, 116, 1095-1115.

Mitchell, J. E. (1998). Densification and improvement of hydraulic fills. Proc., Specialty Conf. on Hydraulc Fill Structures, ASCE GSP No. 21. In D. G. A. Van Zyl \& S. G. Vick, (Eds.). ASCE, New York, pp. 606-633.

Oda, M., Kawamoto, K., Fujimori, H., \& Sato, M. (2001). Microstructural interpretation on reliquefaction of saturated granular soils under cyclic loading. Journal of Geotechnical and Geoenvironmental Engineering, 127, 416-423.

Puebla, H., Byrne, P. M., \& Phillips, R. (1997). Analysis of CANLEX liquefaction embankments: Prototype and centrifuge models. Canadian Geotechnical Journal, 34, 641-657.

Poulos, S. J., \& Hed, A. (1973). Density measurements in a hydraulic fill. Evaluation of Relative Density and its Role in Geotechnical Projects Involving Cohesionless Soils, ASTM STP 523. In E. T. Selig \& R. S. Ladd, (Eds.), ASTM, West Conshohocken, PA, pp. 402-424.

Seed, H. B., \& Idriss, I. M. (1971). A simplified procedure for evaluating soil liquefaction potential. Journal of Soil Mechanics Found Division, ASCE, 97(SM9), 1249-1273.

Seed, H. B., Wong, R. T., Idriss, I. M., \& Tokimatsu, K. (1986). Moduli and damping factors for dynamic analyses of cohesionless soils. Journal of Geotechnical Engineering, ASCE, 112, $1016-1032$.

Skempton, A. W. (1986). Standard penetration test procedures and the effects in sands of overburden pressure, relative density, particle size, ageing and overconsolidation. Geotechnique, 36, 425-447.

Suzuki, H., Tokimatsu, K., Sato, M., \& Abe, A. (2005). Factor affecting horizontal subgrade reaction of piles during soil liquefaction and lateral spreading. In R. Boulanger \& K. Tokimatsu, (Eds.), Seismic performance and simulation of pile foundations in liquefied and laterally spreading ground (pp. 1-10). Geotechnical Special Publications No. 145.

Tamura, S., \& Tokimatsu, K. (2005). Seismic earth pressure acting on embedded footing based on large-scale shaking table tests. Geotechnical Special Publications, 145. In R. W. Boulanger \& K. Tokimatsu, (Eds.), 2005, pp. 83-96. 
Thevanayagam, S., Kanagalingam, T., Reinhorn, A., Tharmendhira, R., Dobry, R., Pitman, M., ... El Shamy, U. (2009). Laminar box system for 1-g physical modelling of liquefaction and lateral spreading. Journal of ASTM Geotechnical Testing, 32, 438-449.

Tokimatsu, K., \& Seed, H. B. (1987). Evaluation of settlements in sands due to earthquake shaking. Journal of Geotechnical Engineering, 113, 861-878.

Towhata, I., Sesov, V., Motamed, R., \& Gonzalez, M. (2006). Model tests on lateral earth pressure on large group pile exerted by horizontal displacement of liquefied sandy ground. Proceedings of the Eighth US National Conference on Earthq. Eng., no.1227, San Francisco, CA, EERI, Oakland, CA.

O'Rourke T. D., \& Hamada, M. (1992). Case studies of liquefaction and lifeline performance during past earthquakes. United States Case Studies. Tech. Report, vol. 2, no: NCEER-920002, NCEER, SUNY-Buffalo, NY.

Whitman, R. V. (1970). Hydraulic fills to support structural loads. Journal of the Soil Mechanics and Foundations Division, 96, 23-47.

Whitman, R. V. (1985). Liquefaction of soils during earthquakes. Washington, DC: Committee on Earthquake Engineering, National Research Council, National Academy Press.

Whitman, R. V., \& Lambe, P. C. (1986). Effect of boundary conditions upon centrifuge experiments using ground motion simulation. Geotechnical Testing Journal, ASTM, 9, 19-26.

Youd, T. L., Idriss, I. M., Andrus, R., Arango, I., Castro, G., Christian, J., ... Stokoe, K. H. (2001). Liquefaction resistance of soils: Summary report from the 1996 NCEER and 1998 NCEER/NSF workshops on evaluation of liquefaction resistance of soils. Journal of Geotechnical and Geoenvironmental Engineering, 127, 817-833.

Ziotopoulou, K., Boulanger, R. W., \& Kramer, S. L. (2012). Site response analysis of liquefying sites. Geo-Congress, ASCE, 1799-1808. doi:10.1061/9780784412121.185 